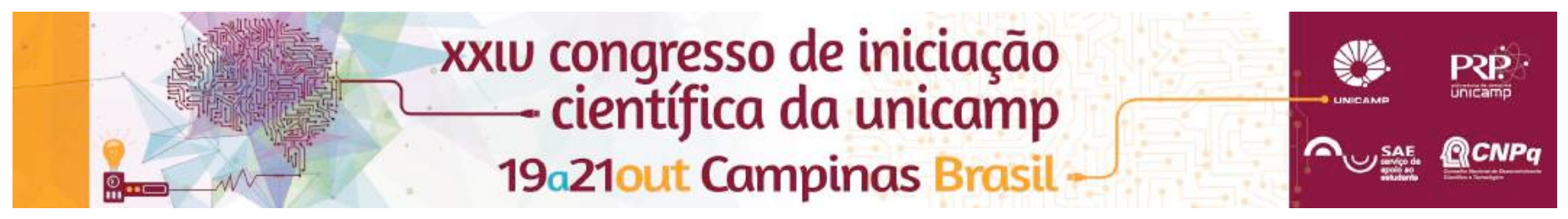

\title{
Representing metabolic pathways in a 3D immersive environment.
}

\author{
Marcio L. Magrini, Eduardo Galembeck, Rodrigo D. Takase
}

\begin{abstract}
The new technologies have been responsible for the development of novel ways to represent, interact and visualize information. The current project aims the development of a novel methodology in the way a metabolic pathway is represented in 3D immersive environments. From a 3D scale cell model, it is possible to interact with the dynamics concerning an entire metabolic pathway. Unlike the traditional 2D paper way to represent the metabolic pathways through flowcharts, this project adds the space and time compounds to pathways representation. Therefore this project brings innovation to the learning of metabolic pathways once it allows the user to navigate inside the cell along with the molecules of different pathways, thereby acquiring multidisciplinary knowledge.
\end{abstract}

\section{Key words:}

Metabolism, 3D, Biochemistry.

\section{Introduction}

We are currently living the age of knowledge, where important changes occur all the time. This affects the way we read the world, exposing ourselves to novel challenges regarding educational issues. This project proposes a new methodology to represent metabolic pathways in 3D immersive environments, where the user is now able to navigate through the cell at the same time the pathway dynamic occurs. In this novel model, the user has the opportunity to visualize the metabolic pathways dynamics occuring inside a cell.

\section{Results and Discussion}

In the first half of this project it has been implemented a MOOC (Massive Open Online Course) environment to The Cell App, as a complementary project. In MOOC, the user learns and is evaluated as interacts with the App. It is divided in four categories. The first one, called Text Content, presents the theoretical content for the selected cell organelle. The second category, called Challenge, defies the user to answer questions related to the selected organelle. The third category, called Training Games, works as a fixation game. At least, the category called Assessment is an evaluation section, where the user may answer different types of questions, as multiple choice and fill the gaps.

The second half of this project represents the implementation of a metabolic pathway into the App The Cell. The pathway chosen to be first implemented was the fatty acid synthesis in an animal cell (Image 1). This novel feature allows the user to follow in real-time how it occurs the synthesis process, since the first molecule till the last one. The entire process is built by the user, where the next pathway reaction only occurs if the user correctly answer the questions or interacts with the correct organelle. If the user chooses a wrong answer a feedback screen is presented, so the user has another chance to pick the correct answer. The pathway will not progress till the user correctly answer the current question.

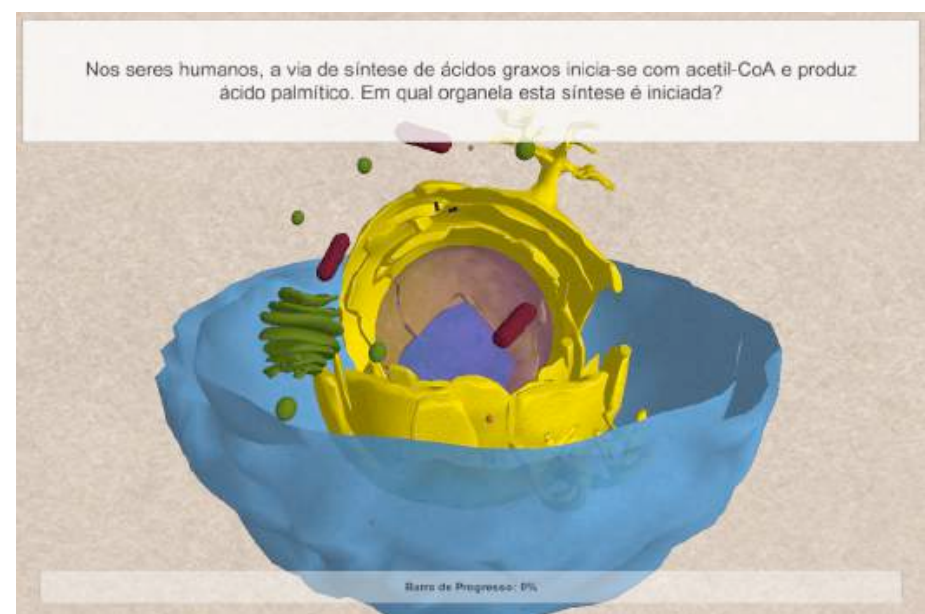

Image 1. App overview: the user interacts directly with the cell as the fatty acid synthesis questions are correctly answered.

\section{Conclusions}

More than a simple update, this project brings new features to the App. It has created a whole novel user interface regarding the learning of metabolic pathways. Furthermore, it represents a new way of creating interactive content, capable of arousing the user interest in biochemistry and other complementary matters.

\section{Acknowledgement}

Conselho Nacional de Desenvolvimento Científico e Tecnológico (CNPq) [National Council for Scientific and Technological Development].

Holden, W., (2009). Mobile Applications \& Apps Stores: Business Models, Opportunities \& Forecasts 2009-2014. pp. 103.

James, R. A.; Rao, M. M.; Chen, E. S.; Goodell, M. A. \& Shaw, C. A., (2012). The Hematopoietic Expression Viewer: expanding mobile apps as a scientific tool. Vol. 28 no. 14, pp. 1941-1942.

Krasilchik, M., (2004). Prática de Ensino de Biologia. São Paulo: Editora USP.

Stark, L. A., (2012). Cell Biology Apps for Apple Devices. CBE Life Sci Educ. Vol. 11, n. 3, pp. 226-230.

Zoller U., (2012). Teaching tomorrow's college science courses - are we getting it right? J. Coll. Sci. Teach. Vol. 29 pp. 409-414. 